\title{
Chapter \#12
}

\section{THE IMPORTANCE OF BILINGUALISM IN THE PRIMARY CLASSROOM}

\author{
Edina Kulenovic \\ Middlesex University, London, United Kingdom
}

\begin{abstract}
The main purpose of this study was to give account of the importance of early bilingualism in the primary classroom and to ascertain if being bilingual from an early age is an advantage or a hindrance. In the context researched here (Primary school teachers and Primary trainee teachers in England), the paper seeks to determine how early bilingualism has influenced the respondents' education, career choices and overall learning and teaching experience at school. Action research was used in this study. The key findings concluded that early bilingualism has impacted positively on the respondents' education and life choices and that being bilingual from an early age is an advantage. On the other hand, there are some negative influences, but they are outweighed by the benefits that knowledge of home languages bring. It is hoped that this study will encourage primary teachers, trainee teachers and parents to look at bilingualism as an opportunity and utilise bilingual learners' linguistic and cultural knowledge in order to create an environment where students and teachers have the opportunity to learn and develop together.
\end{abstract}

Keywords: bilingualism, language acquisition, proficiency, classroom practice, impact.

\section{INTRODUCTION}

We live in a global melting pot. As the world gets smaller by the day and the means of communication, including languages, are changing fast, we need languages more than ever in order to communicate with people around us (Li, Patel, \& Sooknanan, 2011). Although there is a significant amount of literature focused on the need for knowledge of additional languages (Conteh, 2012), early exposure to bilingualism has been chosen for this research Educational advantages and disadvantages of bilingualism have been the target of investigations since the 1920s (Cunningham, 2011). It is an important and much-discussed topic, which may evoke both positive and negative emotions (Robinson \& Altarriba, 2014). According to Ramirez and Kuhl (2016), about two thirds of the world's population is now estimated to understand or speak at least two languages; bilingualism has become the norm rather than the exception in many parts of the world. However, not everyone agrees that knowledge of these languages is helpful or beneficial (Bialystok, Craik \& Luk, 2008).

\section{BACKGROUND}

The author's interest in this area has originated from her practice as a former primary school teacher in the UK. She noticed that a number of parents were reluctant to maintain learning in class home languages and only equated academic success with learning in English, the 'dominant' language. They wanted to replace home languages with English as 
soon as they could in order to integrate into the 'dominant' society. Even some teachers at school had shown no interest in bilingual children's culture and educational advantages that came with it. Javier (2007) recommends finding areas of strengths for each child rather than finding exclusive areas of deficiencies. He suggests avoiding tests that are too loaded in linguistic and cultural demands, especially if a newly immigrant child is being assessed.

The author's interest in this topic has increased further since becoming a teacher educator at the University. Having conducted a survey amongst primary trainee teachers, it was clear that a significant number of them was not able to recognize nor utilise fully bilingual children's existing knowledge and language skills. Javier (2007, p. 14) wonders if it could be due to "anxiety" associated with the presence of another language, that is not familiar to the "dominant" members of our society. Similarly, Byers-Heinlein \& Lew-Williams (2013) suggest that some professionals may think that bilingualism causes delay in language acquisition and a possible decrease in vocabulary in both languages.

It was hoped that this study would establish if early bilingualism is helpful at primary school and if it can be used by teachers to foster a positive classroom environment where pupils and teachers have the opportunity to learn and develop together.

\section{LITERATURE REVIEW}

This section provides an overview of the literature that underpins this study.

\subsection{The earlier, the better}

Academic opinion varies over the extent to which an early start in second language learning influences higher level proficiency later on in life. Despite insufficient empirical evidence, there was an "enormous boom of interest" (Moon \& Nikolov, 2000, p.v35) in early second language instruction in the 1990s, and it still remains a much-debated issue. Neurolinguists have been interested in bilingual brains for a long time and the way language is configured for bilingual people. Cameron (2001) supports the view that young children learn languages more effectively than adults, especially before puberty. At that age they use parts of the brain and mechanisms that are no longer accessible in later life. She illustrates the concept of the Critical Period Hypothesis $(\mathrm{CPH})$, which represents Lenneberg's notion of a 'critical period' for language (1962). Lenneberg argues that the development of specialization of functions in the left and right sides of the brain begins in childhood and is completed at puberty. Although the "bilingual brain is still terra incognita", (Grosjean, 1982, p. 267) it seems that modern research may be shifting towards supporting Cameron's view (Bialystok, 2016). Similarly, Vygotsky (1962, p. 43) observes that speech and thought are independent at first, but begin to merge at around the age of two. At around that time "the knot is tied for the problem of thought and language". His view was that there was a profound connection between children's language and the early development of cognitive awareness and mental concepts.

\subsubsection{Benefits of early bilingualism}

In the literature one can find many examples of acknowledgement of the benefits of early bilingualism, which may be helpful to teachers. For instance, Baker (2006) notes that the ownership of two languages is increasingly seen as an asset as the communication world gets smaller. He also suggests that bilinguals' role is to preserve a linguistically and culturally diverse world. Bialystok (2001, p. 192) argues that bilingual children's ability to read and some of the components that prepare children for it transfer across languages and systems. If children have those skills in one language, they may apply them to the other 
one. Sneddon (2000) reflects on the relationship between literacy at home and at school; his study shows that language and literacy skills are transferable between languages and that the knowledge of a home language lays a good foundation for successful learning in a majority language. Similarly, Baker (2007) notes that bilingualism may increase children's thinking power. For instance, corresponding words in different languages may have different connotations. As bilingual children have different association for each word, they "... may be able to think more fluently, flexibly and creatively" (Baker, 2007, p. 5). Ramirez and Kuhl (2017) show that the accumulating effect of dual language experience is effective against cognitive decline that comes with ageing and may delay the onset of Alzheimer's disease. Bialystok (2016) thinks this is due to the "cognitive reserve" in the brain, which is boosted by bilingualism rewiring the brain. According to her theory, in case of damage, bilinguals can compensate more because they have extra grey matter and alternative neural pathways.

Ramirez and Kuhl (2017) reflect on a growing body of evidence which suggests that bilinguals (from an early age) exhibit enhancements in both executive functioning and cognitive flexibility, which aids problem solving and planning. As the brain switches from one symbolic code to another and makes the effort of constantly managing attention to the target language, various brain networks are strengthened and enhanced. Moreover, bilingual learners have increased empathy, as learning a language requires careful listening to others and paying more attention to communication rather than speech errors. Nikolov (2000, p. 42) notes that second language learning can "...encourage the early understanding and appreciation of different cultures and values..." Research also suggests that bilinguals may be more sensitive during communication as well as 'more patient than monolinguals' (Baker, 2007, p. 5). Bilingual children's level of self-esteem is also higher, as they are able to switch between different languages. They are secure in their own identity.

Other advantages of an early start include access to enhanced employment prospects and rewarding career opportunities. Having a personal connection to a country or a language can help bilinguals understand other ways of life more effectively. Baker (2006, p. 423) observes that bilinguals are highly employable in almost all areas of business, be it tourism, banking, media, the medical profession, international transport, marketing, ICT, teaching, interpreting or government work. Interacting with customers in their own language is good for business. Carreira and Armengol (2001) and McGroarty (2002) note that bilinguals are often seen as more multi-skilled. Bilingualism can "become a marketable ability to bridge languages and cultures, securing trade and delivery of services" (Baker, 2006, p. 425). Although bilingualism does not "guarantee a meal ticket or future affluence" (Baker, 2007, p. 5) bilingual people are likely to be in a strong position in the competitive job markets.

\subsubsection{Limitations of early bilingualism}

This section will explain some of the perceived disadvantages of early bilingualism, that have been repeatedly associated with the process. Some authors are concerned that bilingualism puts children at risk of language delay or academic failure. Javor (2017) reflects on the assumption that early bilingualism affects the development of the mind in a negative way, as two languages disturb each other. Ramirez and Kuhl (2017) refer to several studies which report that bilinguals lag behind in grammar. Hoff et al. (2012) note that bilinguals control a smaller vocabulary in each language than monolinguals, when skills are measured on a single language. Similarly, Bialystok et al (2008) report about negative effects of bilingualism such as poorer lexical access and receptive vocabulary. As bilinguals split their time between two languages, they have less time for each language 
than monolingual children. In a way, these results are not surprising. Nikolov (2000, p. 25) observes how the existence of a 'critical period' has been argued against by some researchers and that "older language learners are more successful and efficient that younger learners". Similarly, Singleton and Ryan (2004, p.4) observe that some studies point out that the existence of 'critical period' is not proven and that, in fact, older beginners do better. They favour a later start.

The view that home languages somehow 'destroy' children's learning in English may still be present. Even David Blunkett, the former Education Secretary, suggested that children can only learn one language at a time and that learning a mother tongue interferes with English (Casciani, 2003). However, Piper (2001, p. 12) observes that "...young children acquire two or more languages in much the same way as they learn different registers - socially defined varieties - of the same language". She argues that contrary to some views, bilingualism is an advantage and does not harm children.

Hall (2001, p. 2) wonders why, despite linguistic diversity being a norm in today's UK classrooms, educational literature is still produced with little reference to the fact that British society is multilingual and multicultural She observes that some teachers today "still equate a lack of English language skills with learning problems and low intelligence". Baker (2006) observes that minority languages are often thought of as being connected with problems of underachievement in school, poverty and lack of integration into the majority culture. The author witnessed various forms of assessments in schools that were too complicated and overloaded with challenging vocabulary and cultural references. Similarly, Cummins (1996) suggests that bilingual children's cognitive abilities are often considered to be synonymous with their level of English. This view chimes well with Datta's (2007), who started teaching in the UK in 1976, and was saddened to have found out that bilingual children were embarrassed about their home language. They tried to hide it and were obviously uncomfortable about their bilinguality. As they lacked motivation to learn English, the teachers thought that their bilingualism is "a handicap to learning". Moreover, parents may equate academic success with learning in English only. Conteh (2003) observes how some parents face dilemmas while attempting to involve themselves in their children's education. They have a strong sense of cultural identity and work hard on maintaining their home languages and cultures. However, they recognise the need to become proficient in English and work hard in order to succeed at school and later on in life. Enever, Moon, and Raman (2009) observe that some parents are keen for their children to be proficient in English first, as English is perceived as a universal world language, used for international communication and trade.

Some studies show that there is still a gap in general awareness of the needs of bilingual learners (Conteh, 2012). That is perhaps the biggest obstacle to effective teaching and learning. Enabling access to a broad and balanced curriculum, that involves parents and home cultures, can indeed be a challenging task. Some teachers may find it very difficult to cope with an ever-increasing workload and simply cannot find the time and energy to devote to their bilingual learners, let alone to talking to parents. Conteh (2003, p. 48), is concerned about some teachers who, due to the pressure of meeting targets, provide 'pre-packaged, uniform teaching that takes no account of their pupils' experiences.' She highlights that, as the benefits of bilingualism are long-term, rather than short-term, they are not exploited in most mainstream classrooms in England. Hall (2001, p. 6) stresses that the most important thing teachers and schools should remember is to look at the home language as a "valuable channel and NOT a hindrance". However, this process will not take place overnight. Ideally, schools should be able to handle all of these matters sensitively and sensibly. Furthermore, they should make sure that policies and the curriculum are 
planned carefully to cater for bilingual children's needs, that they involve parents and that they reflect the need for continuity and sustainability. Only then will teachers be able to help their learners to fully utilise their cultural and linguistic experiences (Conteh, 2012).

This section has explained the benefits and limitations of early bilingualism. It is hoped that different views of early bilingualism will be beneficial to practitioners and encourage them to look at bilingualism from different perspectives.

\section{METHODOLOGY AND INVESTIGATION}

Sixteen respondents volunteered to take part in this survey - twelve primary student teachers from University and four experienced primary teachers from partnership schools. All of them teach bilingual children in their classrooms. In addition, eight of them are bilingual, so they were able to provide valuable insight into the impact of home languages on their own education, overall learning experience and career choices. The response rate was $100 \%$. Action research was chosen for this study. Sharp (2009) suggests that this is a suitable approach as it can help teaching staff find answers to questions they face every day. In addition, it helps them to address specific concerns and issues they may have. McNiff (2013) explains that action research is an effective way of evaluating of what we are doing, while improving our own work and that of others at the same time. McGrath and Coles (2010, p. 109) observe that sharing good practice with other professionals will "spread out like ripples on a pond" and have a positive effect on other researchers' practice.

Researchers incur serious ethical obligations toward their respondents (BERA, 2018) The author was aware that bilingualism may potentially be a sensitive issue for some participants. Language allows speakers to articulate and conceal their feelings; this can have significant impact on their emotional understanding and experience. Newby (2014, p. 318) explains that researchers need to be aware of possible strong reactions, but the questions still had to be asked. He notes that the key ally in producing questions is 'the privacy of the questionnaire and the anonymity we should afford the respondent'. Newby (2014) also explains that the way to capture the participants' interest is to explain the purpose and possible outcomes of the research as succinctly as possible. In addition, the significance of their contribution should be explained and the questions should be straightforward. In order to ensure anonymity and confidentiality, each respondent was assigned a code. Ethical consent was taken into consideration and additional information was provided during face-to-face meetings. The participants were informed that the research was also an opportunity for them to explore and reflect on their understanding of bilingualism and their own experiences, in order to improve their classroom practice. Similarly, Cohen, Manion, and Morrison (2011) note that action research bridges the gap between research and practice and importantly, it makes education practice more reflective. Reflection helps us gain insight and move forward. Austin (2016) advises trainee teachers to answer all questions regarding their classroom practice from an informed and substantiated position. That can only be achieved by approaching teaching from a thoughtful and reflective perspective.

The research method involved semi-structured, individual interviews and three quantitative questions, in order to allow for more diversity in responses and to be able to adapt to new developments during the study. The qualitative questions were prepared in advance and the interviews were recorded. Newby (2014) suggests that the conclusion should be reached by reflecting on data consistently, without prejudice, in order to avoid bias. The respondents' answers were pursued in order to follow through interesting ideas and themes which arose during the interviews. Notes were taken in case the interviews ran 
dry or if note-taking had to be reverted to in an emergency. Woods (1986, p. 81) suggests that during interviews, “...even the briefest of notes can aid recall ... The cryptic joints made at the time are sufficient to stir memory later'. Primary evidence was used, which meant original and uninterpreted information, provided by the respondents, was analysed. Newby (2014) observes that in semi-structured interviews, interviewers have the freedom to clarify people's understanding, explore viewpoints and ask follow-up questions. Bell (2005) highlights that one major advantage of this approach is its adaptability. The way in which a response was made, such as facial expression or gestures can provide much more information than a written response. Solid, measurable data were needed too; therefore three quantitative questions were asked. The answers are presented in the 'Survey results' section. Bar charts were used to collate specific elements of findings in this section and to highlight key elements to the reader. Austin (2016) observes that presenting these key aspects of the data makes it easier for the reader to follow when it comes to the analysis.

\section{SURVEY RESULTS}

After the interviews, a quick analysis of the data was done by looking at patterns and how the answers related to the questions that were asked. More time was given for a fuller analysis later on. Some answers were slightly unexpected. McGrath and Coles (2010) advise this approach to analysing data, in order to avoid closing researchers' minds to other possibilities, such as patterns, surprises, the unexpected.

Figure 1 .

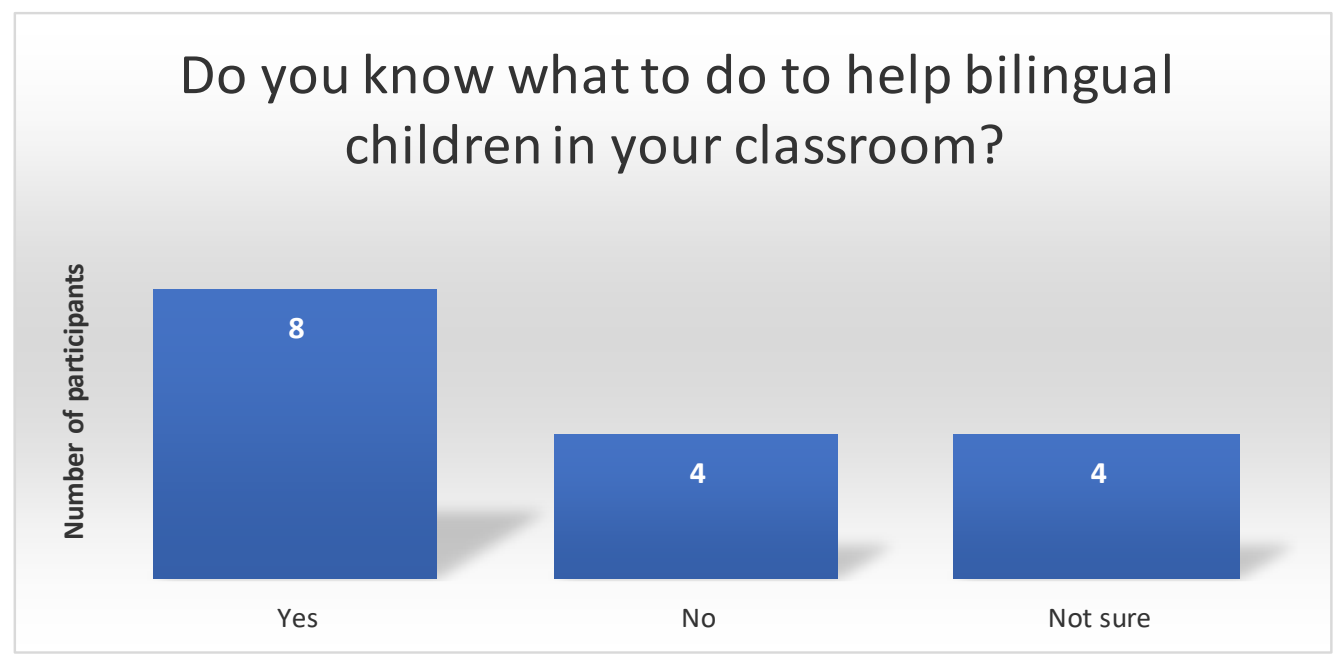

Figure 1. shows a mixture of results. $25 \%$ of respondents did not know how to help bilingual children in their classroom and $25 \%$ were not sure. This was a slightly unexpected outcome, as a higher percentage of the "Yes" answer was expected. However, all respondents expressed desire to learn more about bilingualism, in order to improve their practice, and some expressed frustration with the lack of support from schools. 
Figure 2.

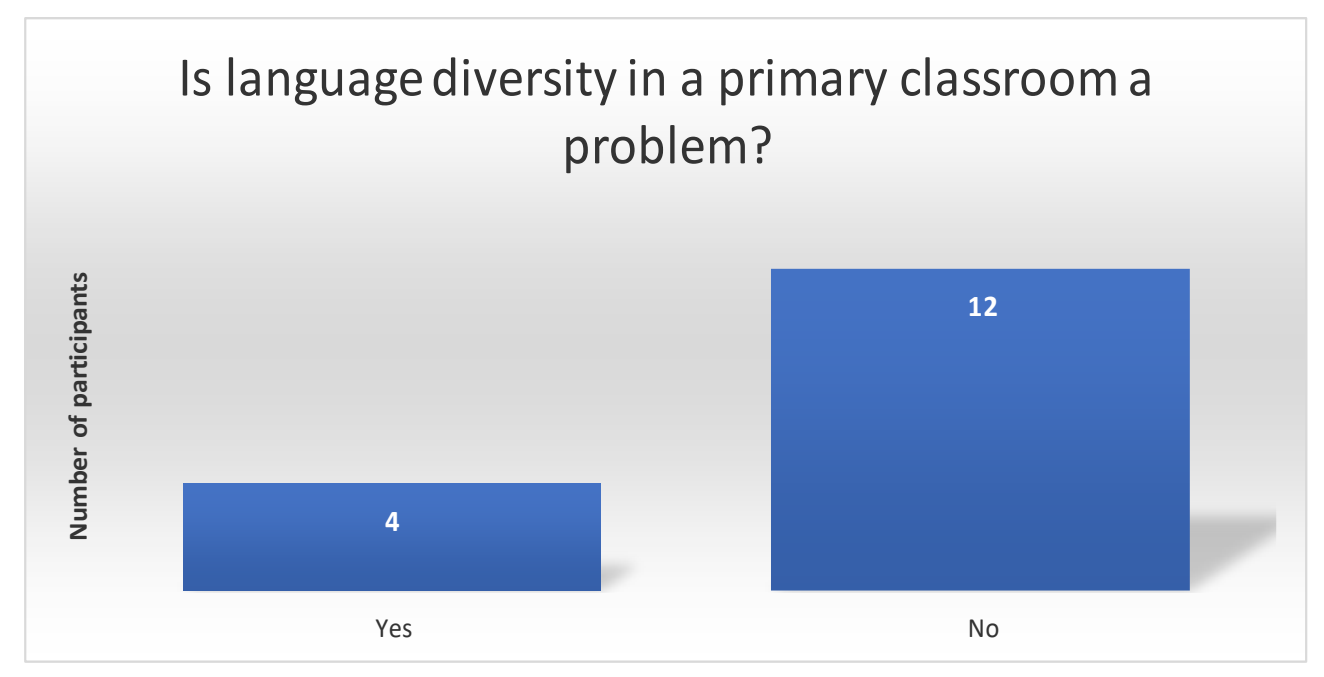

This was an interesting outcome. Figure 2. suggests that $25 \%$ of respondents think that language diversity is a problem in a primary classroom. They think that bilingualism might be an obstacle to learning and it would be best if children spoke English only at school. In addition, they said that some bilingual children they teach insist that they do not want to speak their home languages in public, especially with their parents, as this attracts unwelcome attention.

Cunningham's (2011) highlights the difficulties young children may experience when living with two languages. They attempt to analyse the stream of sounds into meaningful units and later they need to learn two words for everything and two systems of putting words together. This may lead to frustration and failed communication. Older children are expected to achieve literacy in both languages as quickly as possible, so they can perform well at school; this can be a daunting task. Cunningham (2011) adds that for some children, speaking a different language will attract attention. They may not be willing to be seen in public with their minority language-speaking parents for fear of being spoken to in the minority language.

The respondents who said that language diversity in classroom is a problem for them also stated that they lack training and that they simply do not have the time to prepare extra resources or do extra research, in order to accommodate bilingual children's learning. One respondent felt intimidated by their pupils' bilingualism and did not know how to help them. But the majority of respondents suggested that taking advantage of children's home cultures and experiences can be used as catalysts for interesting conversations and a springboard for projects in all areas of the curriculum. English speaking children can get involved, so everyone benefits (Issa \& Öztürk, 2007). 
Figure 3.

\section{Early bilingualism - an asset or a hindrance?}

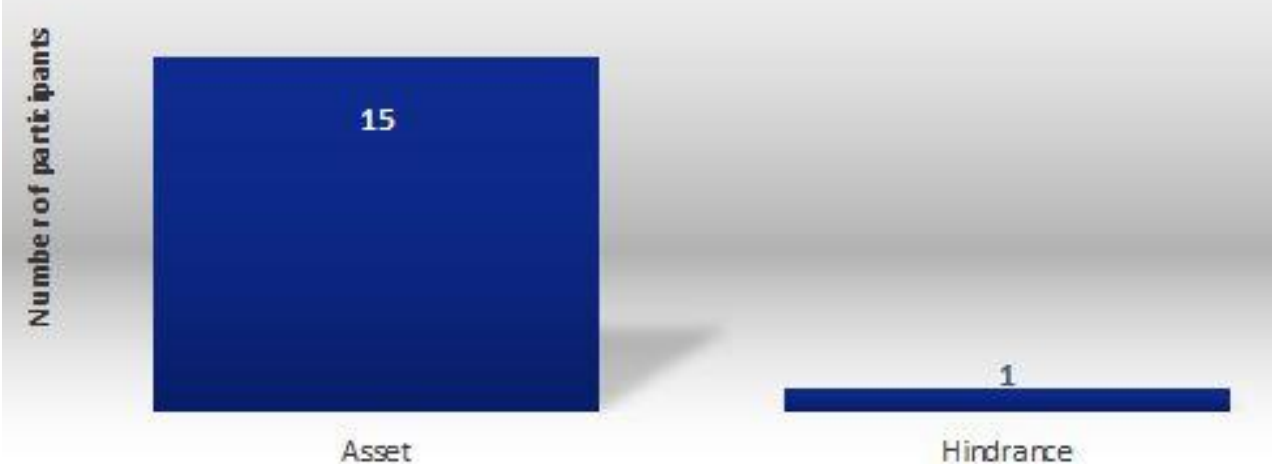

As shown in Figure 3, 94\% of respondents have agreed that early bilingualism is an asset overall. They have noticed that, despite potential difficulties mentioned in Figure 2 , bilingual children can learn more quickly and can use their existing knowledge and skills to create effective learning strategies Sanchez-Azanza, López-Penadés, Buil-Legaz, Aguilar-Mediavilla, and Adrover-Roig (2017) observe that, in recent years, the behavioural performance of monolingual and bilingual participants has become a theme of debate and a controversial topic in cognitive science. Their study supports the idea that bilinguals show enhanced cognitive control capacity when compared to their monolingual peers. This phenomenon is known as 'bilingual advantage'.

To summarise, the majority of the respondents (94\%) agreed that early bilingualism is an advantage and they send a strong message to bilingual children. "Your home language is a very precious skill. Don't be ashamed of it; embrace it."

\section{DISCUSSION OF FINDINGS}

The main findings of the study are cited below.

\subsection{Knowledge of home languages improves communication}

The majority of respondents $(81 \%)$ have stated that one of the main benefits is improved communication. Most bilinguals have access to two cultures, which is the only way to experience fully different ways of living, customs, food and drink, beliefs, ideas, art and ways of thinking. Baker (2007) agrees that the main advantage of speaking two languages is the ability to communicate. Likewise, Cunningham (2011) notes that this ability gives bilinguals a sense of pride and achievement. By using their home language, the child builds relationships with the extended family or the wider community and feels a sense of belonging and identity. Similarly, Robertson, Drury and Cable (2014, p. 611) refer to children's and families "funds of knowledge" (resources, competencies, values and assumptions), that are developed through social networks and life experiences. 
Bridging generation gaps is another important role. The respondents in this study found that their respective home languages help them communicate with the grandparents, relatives and other members of the community, which increases their sense of belonging.

\subsection{Good classroom practice and positive, inclusive ethos are essential for effective teaching and learning}

A common thread through this study was the respondents' willingness to learn more about bilingualism and how it affects learning and teaching. 25\% of them (even those who are bilingual) found that they did not really know how to help bilingual children in their classroom, but they all wanted to learn more.

$40 \%$ of bilingual respondents expressed frustration with their teachers during early years of education. They found that the teachers looked at their bilingualism as an obstacle to learning. Some of them were even put in lower ability groups unnecessarily and received very little support from schools when they were settling in. Three respondents said that their home culture and language were totally ignored by their teachers, but this has made them even more determined to succeed at school. Whitehead (1990, p. 84) notes how important it is for educators to look at children's "underachievement" against a wider cultural background, as culture and language go hand in hand. Accordingly, teachers should be able to understand and listen to their pupils and families without prejudice, as 'they too may learn to move more easily and confidently between language worlds and culture'. Grosjean (1982, p. 158) talks about difficulties people may experience when adapting to a new culture, which educators should be aware of. It can be a trying experience and can result in "loneliness, hostility, self-pity, disorientation, and fear of ridicule." Classroom practitioners should bear these factors in mind when dealing with newly arrived immigrant children and parents.

One bilingual respondent had a positive learning experience at school, as the school employed a few bilingual teaching assistants, who were always ready to help and interpret. They provided stable emotional support to children and were valuable links between home and school. Enever et al. (2009) observe that enthusiastic and trained teachers, together with a rich and stimulating learning environment, should be able to provide good quality provision. Kelly (2010, p. 95) advises that interactions are more likely to be productive in schools which send consistent messages that home practices count "because they are part of the children's experience". This effective learning practice should enable children access to a balanced curriculum, show them that their home cultures are valued at school and ultimately, have a positive effect on their learning.

\subsection{Increased parental involvement is crucial to success both at school and at home}

94\% of respondents suggested that increased parental involvement is vital in ensuring effective learning. They thought that successful cooperation between teachers and parents is essential and can make all the difference. Supportive parents can motivate children by showing genuine interest and a positive attitude towards learning in both languages and praise progress, no matter how small.

A significant number of bilingual respondents (43\%) said that their parents were reluctant to get involved in their education. They thought of English language as the 'superior language' and only wanted their children to use English at school and even at home. The respondents often felt ashamed of their home languages and did not want to speak it in public with their parents. The Bell Foundation (2017) advises immigrant parents 
to encourage children to feel proud of their home language and culture and to be actively engaged in school life. Conteh (2012) suggests that one of the ways for establishing an effective relationship between parents and teachers is for teachers to report children's achievements to their parents and providing parents with an opportunity to discuss their children's progress. Arrangements for reporting may differ according to parents' linguistic and cultural background, but teachers can find creative ways of resolving this (e.g. the child or a family member may interpret). Baker (2006) suggests making use of bilingual teachers and teaching assistants as an effective strategy. This will make children and parents feel more involved and appreciated by the school.

\subsection{Children's home culture and identity go hand in hand with language}

The majority of respondents $(87 \%)$ observed that language, culture and identity are closely related. One cannot exist without the other; they shape who we are.

A surprising $60 \%$ of bilingual respondents reported that their schools largely ignored their home language and culture. This approach made them feel insecure and sometimes silent; consequently their silence was interpreted as low academic achievement. One respondent was teased by other children about the food they ate and the music they listened to. The teachers did not do anything about it. Cummins $(1996$, p. 2) observes that in the past, "schools' rejection of students' language and culture tended to reflect the broader society's subordination of cultures and languages other than those of the dominant group". In addition, sometimes bilingual children may experience an identity crisis and not feel comfortable with having two identities and constantly moving between them. Identity is often imposed and being a member of a 'minority' may bring stress and tension to one's life.

$90 \%$ of respondents agreed that careful planning and taking children's background into consideration is of crucial importance for any policy planning and implementation. The OFSTED report $(2005$, p. 3) illustrates the importance of recognising pupils' linguistic backgrounds in order to improve their attainment. The report notes how in most institutions there was "little systematic analysis of students' linguistic backgrounds or the impact of bilingualism on academic achievement". However, in those schools where senior managers did collect this information, it was successfully used to provide appropriate resources to help students, which contributed towards raising their standards of work. The report also stresses how some schools actively encouraged students to take GCSEs (General Certificate in Secondary Education) in community languages and their achievements were greatly valued and a source of pride for the whole school.

$40 \%$ of respondents said that the children in their classrooms reacted very positively to their culture and identity being recognised, e.g. registers being taken in home languages, bilingual stories being read and different songs being sung Moreover, parents enjoyed being invited to class and talking to the children about their customs, language and food. By promoting bilingual children's mother tongue and cultural heritage, teachers show them that their culture and identity is validated; therefore, the whole child has been accepted. "This process forms the basis for meaningful learning" (Issa \& Öztürk, 2007, p. 18).

\subsection{Promotion of the home language at school helps develop children's cognitive abilities in the majority school language}

$75 \%$ of respondents observed that they believe their home language has contributed significantly to the development of their own cognitive abilities. They said that the bilingual children they teach are better at switching between tasks and they can focus better on relevant information and ignore distractions. These observations fit in well with research 
carried out by the University of Groningen (2012); the results show that bilinguals often perform better on tasks that require conflict management, as they are better than monolinguals at ignoring irrelevant information Javor (2017) observes that in a research on performance of bilingual and monolingual children, the bilingual children actually performed better than their monolingual counterparts, despite low expectations in non-verbal tasks (such as symbol manipulation and organisation). This evidence shows that bilinguals have greater cognitive flexibility and a diverse set of mental abilities.

\subsection{Knowledge of home language enhances career opportunities}

$70 \%$ of respondents have said that knowledge of two languages has enhanced their career and employment prospects. They felt that their early bilingualism has made them more tolerant and more open minded to new ideas and perspectives at work It has also brought economic advantages, as some of them were able to find careers that required knowledge of additional languages, such as retail, hospitality, NHS and interpreting jobs. They also said that their bilingualism has brought practical advantages at work, such as increased salary packages and securing business deals. Two respondents said they will go back to teach in their home countries once they finish their teacher training. They are confident that the language competence in two languages will be an advantage over other candidates. United Education Institute (2017) confirms that knowledge of languages can lead to successful and rewarding career opportunities.

\section{FUTURE RESEARCH DIRECTIONS}

The number of respondents in this study was limited to sixteen; however, the project could be a beneficial preparation for a possible larger study with a higher number of participants. It is envisaged that primary school practitioners, including trainee teachers, would benefit from a larger, more in-depth study on understanding the cognitive benefits of bilingualism and implementing good practice in teaching bilingual children in primary schools.

\section{CONCLUSION}

This study has given account of the importance of early bilingualism and its role in the primary classroom. The evidence has illustrated that the benefits outweigh negative influences, providing optimal conditions are created: increased teacher awareness, effective teacher training, a positive and stimulating learning environment, parental involvement and continuity in effective practices. As the world changes and the means of communication, including languages, are changing faster than ever before, the future of languages is complex and multi-faceted. The debate on value of bilingualism is likely to continue and will probably remain a much-discussed and prominent feature in the education sector for a long time.

It is hoped that this study will encourage practitioners and parents to view bilingualism as a tool which can improve teaching and learning in the primary classroom. If there is to be a wider impact on practice, the research must be shared with the staff and trainee teachers within the institution, as well as partner schools and at learning and teaching conferences. This implies a positive impact on practice. 


\section{REFERENCES}

Austin, R. (2016). Researching Primary Education. London: Sage.

Baker, C. (2007). A Parents' and Teachers' Guide to Bilingualism ( ${ }^{\text {rd }}$ edition). Clevedon: Multilingual Matters.

Baker, C. (2006) Foundations of Bilingual Education and Bilingualism (4th edition). Clevedon: Multilingual Matters.

Bell Foundation (2017). School approaches to the Education of EAL students. Retrieved from https://www.bell-foundation.org.uk/app/uploads/2017/05/2014-cambs-Full-Report-FV.pdf

Bell, J. (2005). Doing Your Research Project (4 ${ }^{\text {th }}$ Ed.). Maidenhead: Open University Press.

BERA (2018) Ethical Guidelines for Educational Research, Retrieved from https://www.bera.ac.uk/resources/all-publications/resources-for-researchers

Bialystok, E (2001). Bilingualism in Development: Language, Literacy, and Cognition. Cambridge: Cambridge University Press.

Bialystok, E. (2016, August 7). Why being bilingual works wonders for your brain, Retrieved from https://www.theguardian.com/science/2016/aug/07/being-bilingual-good-for-brain-mentalhealth

Bialystok, E. \& Craik, F. \& Luk, G. (2008). Cognitive Control and Lexical Access in Younger and Older Bilinguals. Journal of experimental psychology. Learning, memory, and cognition, 34(4). 859-873. doi: 10.1037/0278-7393.34.4.859.

Byers-Heinlein, K., \& Lew-Williams, C. (2013). Bilingualism in the early years: What the science says. LEARNing Landscapes, 7(1), 95-112.

Cameron, L (2001) Teaching Languages to Young Learners. Cambridge: Cambridge University Press.

Carreira, M. \& Armengol, R. (2001). Professional opportunities for heritage language speakers. In J. K. Peyton, D. A. Ranard, \& S. McGinnis (Eds.). Heritage languages in America: Preserving a national resource (pp. 109-142). Washington, DC and McHenry, IL: Center for Applied Linguistics and Delta Systems.

Casciani, D. (2003, November 25). Bilingual Asian Children 'Do Better'. Retrieved from http://news.bbc.co.uk/1/hi/education/3236188.stm

Cohen, L., Manion L., \& Morrison, K. (2011). Research Methods in Education. London: Routledge.

Conteh, J. (2003). Succeeding in Diversity. Culture, Language and Learning in Primary Classrooms. Stoke on Trent: Trentham.

Conteh, J. (2012). Teaching Bilingual and EAL learners in primary Schools. London: Sage.

Cummins, J. (1996). Negotiating Identities: Education for Empowerment in a Diverse Society. Ontario: California Association for Bilingual Education.

Cunningham, U. (2011). Growing up with two languages, ( $3^{\text {rd }}$ edition) Oxon: Routledge.

Datta, M. (2007). Bilinguality and Literacy: Principles and Practice ( $2^{\text {nd }}$ edition). London: Continuum

Enever, J, Moon, J., \& Raman, U. (2009) (Eds.) Young Learner English Language Policy and Implementation: International Perspectives. Reading, UK: Garnet Education.

Grosjean, F. (1982). Life with Two Languages. Cambridge, Mass.: Harvard University Press.

Hall, D. (2001). Assessing the Needs of Bilingual Pupils: Living in Two Languages. London: David Fulton Publishers.

Hoff, E., Core, C., Place, S., Rumiche, R. Señor, M., \& Parra, M. (2012). Dual Language Exposure and Early Bilingual Development. Journal of Child Language, 39(1), 1-27.

Issa, T., \& Öztürk, A. (2007). Practical Bilingual Strategies for Multilingual Classrooms. Leicester: United Kingdom Literacy Association.

Javier, R. (2007) The Bilingual Mind, New York: Springer.

Javor, R (2017) Bilingualism, Theory of Mind and Perspective-Taking: The Effect of Early Bilingual Exposure. Psychology and Behavioral Sciences, 5(6), 143-148.

Kelly, C. (2010). Hidden Worlds. Young children learning literacy in multicultural contexts. Stoke on Trent: Trentham. 
Lenneberg, E. (1962). Understanding language without ability to speak: a case report. Journal of Abnormal and Social Psychology, 65(6),419-425.

Li, M., Patel, F., \& Sooknanan, P. (2011). Intercultural communication: Building a Global Community, London: Sage.

McGrath, J. \& Coles, A. (2010). Education research project companion. Oxon; Routledge.

McGroarty, M. (2002), Language Uses in Professional Contexts. In R. B. Kaplan (Eds.), The Oxford Handbook of Applied Linguistics (pp. 262-274). Oxford: Oxford University Press.

McNiff, J. (2013). Action Research Principles and Practice (3rd Ed.). London: Routledge.

Moon, J. \& Nikolov, M. (2000) (Eds). Research into Teaching English to Young Learners. Pecs, Hungary: University Press.

Newby, P. (2014). Research Methods for Education ( $2^{\text {nd }}$ Ed.). London: Routledge.

Nikolov, M. (2000). The Critical Period Hypothesis reconsidered: Successful adult learners of Hungarian and English. Iral- international Review of Applied Linguistics in Language Teaching. IRAL-INT REV APPL LINGUIST., 38, 109-124.

OFSTED (2005, November), Raising the achievement of bilingual learners. Retrieved from www.ofsted.gov.uk/.../Raising\%20achievement $\% 20$ of\%20bilingual\%20learners\%20

Piper, T. (2001). And Then There Were Two: Children and Second Language Learning. Ontario, Canada: Pippin Publishing Corporation.

Ramirez, N. \& Kuhl, P. (2017). The Brain Science of Bilingualism, Washington DC: National Association for Education of Young Children.

Robinson, C. \& Altarriba, J. (2014). The interrelationship between emotion, cognition, and bilingualism. Yearbook of the Poznan Linguistic Meeting, 1(1). doi: 10.1515/yplm-2015-0006

Robertson, L., Drury, R., \& Cable, C. (2014). Silencing bilingualism: a day in a life of a bilingual practitioner. International Journal of Bilingual Education and Bilingualism, 17(5), 610-623.

Sanchez-Azanza, VA., López-Penadés, R., Buil-Legaz, L., Aguilar-Mediavilla, E., \& Adrover-Roig, D. (2017). Is bilingualism losing its advantage? A bibliometric approach. PLoS ONE, 12(4), $\mathrm{e} 0176151$

Sharp, J. (2009). Success with your Education Research Project. London: Sage.

Singleton, D. \& Ryan, L. (2004). Language acquisition: the age factor ( $2^{\text {nd }}$ ed.). Clevedon UK: Multilingual Matters.

Sneddon, R. (2000). Bilingual Children's Experiences in Multilingual Environments. International Journal of Bilingual Education and Bilingualism, 3(4) 265 -282.

United Education Institute (2017). Can speaking two languages increase your job prospects? Retrieved from https://www.uei.edu/blog/can-speaking-two-languages-increase-your-jobprospects

University of Groningen (2012). Cognitive benefits of being bilingual, Retrieved from https://www.futurelearn.com/courses/multilingual-practices/0/steps/22658

Vygotsky, L. S. (1962). Thought and Language. Cambridge, MA: MIT Press.

Whitehead, M. R. (1990). Language and Literacy in the Early Years: An Approach for Education Students. London: Paul Chapman Publishing.

Woods, P. (1986) Inside Schools: Ethnography in Educational Research. London: Routledge.

\section{ACKNOWLEDGEMENTS}

I would like to thank the Trainee Teachers Focus group at the University and the partner teachers for their time, valuable comments and generous support with this study. 


\section{AUTHOR INFORMATION}

Full name: Edina Kulenovic

Institutional affiliation: Middlesex University

Institutional address: School of Health and Education, Middlesex University, The Burroughs, London, NW4 4BT, United Kingdom

Short biographical sketch: Edina currently works as a Senior Lecturer in Primary Education at Middlesex University, London UK. Her research interests are ethnic and linguistic diversity, English as an additional language and Primary Humanities. 